\title{
Exploring ancient musical ratios
}

\author{
Matin Celhoffer
}

Ancient Greek musical ratios are predominantly interpreted in terms of acoustics on the present. It comes to this, that both string length and frequency are definable through the same ratio, namely the superparticular (superparticularis) ratio of particular frequency corresponds to the reciprocal (subsuperparticularis) ratio of particular string length and vice versa. However, Greeks had not codified frequency, as physical quantitative parameter, and thus experiments with frequency simply could not take place. Only possible measurement could be done according to string length and its fractions by means of the monochord. Although Waerden points out, that monochord emerged as late as in the third century BC. ${ }^{1}$ Therefore, someone may be correct in suggesting that monochord was by all accounts invented after the establishment of musical ratios. The first indisputable evidence of monochord division came back to Euclid's Sectio canonis. ${ }^{2}$ Therefore the technology of musical ratios had to be based on different parameter as that of frequency and length. In any case, monochord was in use since the Hellenic period and allowed theorists to prove their measurements experimentally. However, the way Euclid traced the systema teleion from canon hints that the exclusive operative tool for the tetrachord establishment was geometrical argumentation and not monochord measurement, or in other words: canon served as an idealized monochord, as a model. Of course, this model could be applied also experimentally and thus providing an empirical demonstration of geometrically argumented Greek tonal system. ${ }^{3}$ On the other hand, Aristoxenus - "experimentalist" and disciple of Aristotle, abandoned theories based on musical ratios and treated with musical

1 Waerden, B. L. van de, “Die Harmonielehre der Pythagoreer”, Hermes, 78. Bd., H. 2 (1943), p. 163-199, p. 165.

2 See Mathiesen, Thomas J., "An Annotated Translation of Euclid's Division of a Monochord”, Journal of Music Theory, Vol. 19 (1975), No. 2, p. 236-258.

3 See the reconstruction of Euclidean monochord division in: Celhoffer, Martin, „Sectio canonis. Geometrická konstrukce hudebních intervalů řeckého systema teleion“, Opus musicum, Vol. 44 (2012), No. 2, p. 59-67. See also: Barker, Andrew, "Methods and Aims in the Euclidean Sectio Canonis”, The Journal of Hellenic Studies, Vol. 101 (1981), p. 1-16. 
intervals within tetrachord in way using simple component operation of addition and subtraction - that hints on Egyptian treatment with fractions, and not in cubic system of geometry having being used in Greek ratio definitions. ${ }^{4}$ One could consider Aristoxenus to be experimentalist, though operations of addition and subtraction are not compatible with monochord measurement, contrary to musical ratios applications, and therefore there was no way of experimental verification of his theory of tetrachord divisions.

From these facts it follows that methodology of musical ratios is highly disputable. What was the fundamental touchstone for musical ratio establishment? Was it an acoustical experience, mathematics, geometry, or any combination of them? Through the medium of what tool were musical ratios brought into effect? Was it a simple string stretched on a board that fomented the idea of relation between fraction, string length and pitch, or it happened by an accident, as Nichomachus gives an account of Pythagoras having been passed by blacksmithery when heard the consonance of a pure fifth made by two hammers sized in ratio $3: 2 ?^{5}$

The purpose of this brief study is to find a key for this issue and, not at least, to shed some new light on an anthropological background for methodology of musical ratios in general. The detailed description of various kinds of intonations, temperaments and tuning systems till the establishment of the tempered tuning is not our aspiration. On the contrary, I accentuate the role of the emergence of geometric and numeric reception of the real world as a prerequisite for musical ratio establishment. Therefore the starting point of our exploring dates back to the moment when geometry and number occurred in human culture till their association with an experience of hearing.

According to Boyer it was as far back as the Neolithic era when were set up foundations for elementary geometry though as a part of a decorative art. ${ }^{6}$ Some of these decorative patterns (from Mesolithic and Neolithic era) were identical with later tonal mandalas and algebraic yantras discovered in ancient civilizations of the Near East and pre-Vedic India, and finally in Greek. ${ }^{7}$ What was the common feature of these geometric figures and on the basis of what factors they had evolved? Account of that, we try to comprehend in the first instance the emergence of the early decorative art, its purpose and relevance to geometrical understanding. The oldest evidence of the pre-decorative art, usually a bone decorated with simple cuts, are dated back to Paleolithic and Mesolithic era. We should bear in mind that there is a crucial distinction between deliberately sprinkled cuts, grouped cuts indicating elementary counting of an event (e.g. day, full moon etc.), and finally primitive ornaments, later applied to pottery and other utilities. This

4 Winningron-Ingram, R. P., “Aristoxenus and the Intervals of Greek Music”, The Classical Quarterly, Vol. 26 (1932), No. 3-4, p. 195-208.

5 According to Boethius, see: Boethius, Anicius Manlius Severinus, Fundamentals of Music, Calvin M. Bower, Claude V. Palisca, Eds. (New Haven \& London, Yale University Press, 1989), p. 17-19.

6 Boyer, Carl B., A History of Mathematics (New York: John Wiley \& Sons, 1968), p. 717.

7 See McClain, Ernest G., The Myth of Invariance. The Origin of the Gods, Mathematics and Music From the Rg Veda to Plato (York Beach 1984), p. 9-18, p. 43-60 and p. 129-194. 
decorative art we comprehend as abstract art - an expression of inner world in opposite to realism simply or in stylised or schematised way representative of appearances of outer world (voluminous cave paintings). Chronologically, bones with function of counting are dated back to Paleolithic era, while the most of preserved evidence of decorative ornaments originated later in Mesolithic and Neolithic era.

Among the first documented evidences for elementary counting tools are the so-called Lebombono bone (cca 35.000 B.C.) and Isango bone (cca 20.000 B.C.), both found in Africa. The Ishango bone (figure below) appears to be the oldest preserved table of prime numbers and lunar phase calendar, although there are other voluminous speculations about its hypothetic function, what goes beyond the grasp of our study. ${ }^{8}$

For this evidence of early human technology we apply the Harrod's conception of techné, which "is meant to include a tool itself as such, which has a structure, dynamics, and utility or telos, and the invention, reproduction, and method or right way of using that tool." As it will be shown later, the idealized string (monochord) is the technology of musical ratio establishment. Moreover, Harrod points out an important ontological relevance of technology:

A techné has an important impact upon a people's self-understanding. A techné is more than the product of human ingenuity. It manifests the human self - a relation which relates itself to its own self - and its self-becoming; it manifests what it means to be human. The twofold nature of technology as system and relationship to itself reflects the twofold nature of human life and life itself, which, according to biological science (Eigen and Schuster), is guided by a twofold principle of self-organization and self-correction. Self-understanding and self-becoming involves both formation and ethics. ${ }^{10}$

Author claims for applying these techno-hermeneutical principles also to prehistoric and preliterate era. In this respect, the lunar calendar, recorded in the Ishango bone, gives the metaphysical natural cycle. The term metaphysical is meant to express the relation of human consciousness and projection of its dynamics into ever changing phenomena of outer world. In fact, bone cuts could be explained in terms of functionality: by the medium of primitive tool (e.g. flake tool) the Paleolithic man made simple cuts representing simple events. Consequently through the periodicity of these simple events there is a discovery of more complex temporal structure of phenomena. Moreover, periodicity of particular event may relate to periodicity of other event, the alteration of day and night relates to lunar phase, the lunar phase relates to menstrual cycle etc. The counting conferred a stationary order on seemingly discontinued and disconnected natural phenomena, given by correlation of quantitative consequences. Tendency to confer invariable framework on natural events, which is superior to nature as well as to man, led by the path of elementary counting of simple natural events (day, night) as far as the complex calendar records

8 Marshack, Alexander, The Roots of Civilization (NY: Colonial Hill, Mount Kisco, 1991).

9 Harrod, James B., "The Bow: A Techno-Mythic Hermeneutic - Ancient Greece and the Mesolithic", The Journal of the American Academy of Religion, XLIX/3 (1981), p. 425-446, p. 425.

10 Ibid., p. 425. 
(equinox, solstice etc.). The fundamental critical condition for constituting the quantitative ratio of two different events is the common denominator - in this case a day. This codification enabled temporal orientation in accordance to hunt (migration), harvesting, but it also supplied prerequisites for spatial orientation (in terms of architecture, geodetic, travelling). These prerequisites are:

(i) the numeric idealization of event,

(ii) the stable ratios of two or more numeric idealizations (e.g. moon cycle : day = app. $28: 1$ ),

(iii) temporal codification of movements of celestial phenomena (inevitable for navigation).

One could assume that elementary counting tools are precedent to decorative geometric and biomorphic designs, though the recent evidence does not confirm the hypothesis. The oldest known example of early decorative art - a piece of ochre unearthed on a cave in South Africa, dates back to approximately 70.000 years. ${ }^{11}$

This fact suggests that elementary counting and primitive abstract art did evolve independently in their early stage. Contrary to early counting technology, early ornaments - as an abstract art, apparently had neither function nor semantic meaning (as did realistic cave paintings). It might be a matter of controversy, whether these, for example, triangle patterns are mimesis of biomorphic designs or autonomous abstract art based on simple-cut technology. Or, whether they are some kind of entoptic phenomena. ${ }^{12}$ Speaking in terms of Harrod's techno-hermeneutical principles, we regard this early evidence of decorative art as manifestation of psycho-motorics equilibrium and thus autonomous and non-symbolic exposure of tendency to inner symmetry. The common feature for this ochre and some other early decorative art evidence dated back from later period is the triangle pattern. This fact confirms the hypothesis of inner symmetry requirement: the similar principle is believed to be realized in dance - the step forward followed the step backward, and in dual nature of simple movements - progress of any movement is defined by increasing tension resulting other movement in opposite direction. In terms of modern physics, this proto-form is analogous to any kind of oscillation - electromagnetic or acoustical. The square patterns occurred much more lately in Neolithic era (after the Neolithic revolution), usually as a part of pottery decoration and often executed by dots (as it is shown in table of square numbers below).

11 For example, discovery of oldest decorative art evidence first time published: Whitehouse, David (ed.), BBC News Online science, Thursday, 10 January, 2002, http://news.bbc.co.uk/1/hi/sci/ tech/1753326.stm, accessed: 15/6/2007/15:17.

12 See J. D. Lewis-Williams, T. A. Dowson, Paul G. Bahn, H.-G. Bandi, Robert G. Bednarik, John Clegg, Mario Consens, Whitney Davis, Brigitte Delluc, Gilles Delluc, Paul Faulstich, John Halverson, Robert Layton, Colin Martindale, Vil Mirimanov, Christy G. Turner II, Joan M. Vastokas, Michael Winkelman and Alison Wylie, "The Signs of All Times: Entoptic Phenomena in Upper Palaeolithic Art”, Current Anthropology, Vol. 29 (1988), No. 2, p. 201-245. 
By means of these two examples I briefly demonstrate development of two conceptualisations of the real world: the representation of (i) temporal and (ii) spatial symmetry:

$\begin{array}{lll}\begin{array}{l}\text { Technology } \\ \text { counting }\end{array} & \begin{array}{l}\text { Evidence } \\ \text { Lebombono bone, } \\ \text { Ishango bone } \\ \text { decorated ochre, } \\ \text { Laugerie-Basse bone }\end{array} & \begin{array}{l}\text { Representation of } \\ \text { temporal symmetry }\end{array} \\ \text { decoration } & \text { spatial symmetry }\end{array}$

It is worth of mention that abstract-decorative proceeding, in opposite of counting technology, was in its early stage (i.e. during the pre-commercial society) far from goal directed, to survival-oriented behaviour. Although one could dispute its social function within a community (e.g. ritual and religion), the function accredited also to musical behaviour. However, there is an absence of musical practice evidence from Paleolithic era. On that account we should apply comparative methods in considering the early stage of musical culture. Comparing recent musical cultures with those of the past, "the cyclic structure of the octave is the invariant common to all systems of tuning". ${ }^{13}$ As it will be shown later, the ratio of an octave is analogous to basic proportion of triangle and square symmetry. Eminently, the both activities - music and abstract art, led through spontaneity to prodigiously identical invariances across cultures, which were codified subsequently by means of geometry and mathematics.

One man, one day, one moon cycle etc., have common quantitative parameter one. This parameter is preserved in most languages as the indefinite article. Radical turning point was made when number lost its reference to particular object (temporal or spatial) and became idea. The idealization of number was executed by identifying quantitative parameter and abstract form. This modification was made through its application to abstract art. Number became independent from reality and consequently was applied in geometrical figures derived from abstract art. Moreover, the number in combination with decorative patterns acquired area reference and thus there was a need to define relation between line and area. The establishment of mathematical operations of multiplication and addition followed.

Examples of triangle and square numbers derive from decorative patterns representing the process of cubic comprehension of number:

13 McClain, Ernest G., The Myth of Invariance. The Origin of the Gods, Mathematics and Music From the Rg Veda to Plato (York Beach 1984), p. 19. 
The consequence of "triangle" numbers:

$\begin{array}{lllll} & & & & \\ & & & \ldots & \\ & & \ldots & \ldots & \\ 1 & \cdots & \ldots & \ldots & \\ 1 & 3 & 6 & 10 & \text { etc. }\end{array}$

The consequence of "square" numbers:

$\begin{array}{lllll} & & & \ldots \\ & & \ldots & \ldots & \\ & \ldots & \ldots & \ldots & \\ & \ldots & \ldots & \ldots & \\ 1 & 4 & 9 & 16 & \text { etc. }\end{array}$

The formula for consequence of triangle numbers: $a=1 ; b=a+(b-a) ; c=b+(c-b)$ etc. The formula for consequence of square numbers: $\mathrm{a}=1 ; \mathrm{b}-\mathrm{a}, \mathrm{c}-\mathrm{b} \ldots=$ consequence of prime numbers; and at the same time any square number is composition of corresponding and previous triangle number: $4=3+1,9=6+3,16=10+6$ etc. These and similar considerations are trivial and axiomatic. However, they demonstrate that abstract numerical order is drawn from spatial symmetry. Square numbers and triangle numbers are, in fact, applications of a group theory rooted in decorative patterns. In this respect, decorative patterns and bone cuts were precursors to numerals representing natural numbers, and also precursors of basic geometrical and mathematical operations. From whence it follows that spontaneous tendency to spatial and temporal symmetry paved the way for geometry and mathematics. Square numbers rooted in voluminous Neolithic pottery gives an important anticipation of the square function and, surprisingly, of the mathematical multiplication (e.g. Egyptian mathematics, whence it follows, that methodology of multiplication stems from addition).

Important turning point in the development of geometry, mathematics and music was collapse of Mycenaean empire. At a socio-cultural point of view, this was the assumption for establishment of the Greek Polis during the period of $8^{\text {th }}$ and $7^{\text {th }}$ century BC. The centralization of the politic power had transferred from the hands of monarch to the institution of Polis. Instead of both political and religious authority incorporated into monarchy, the necessity of social equilibrium came into existence. According to Vernant (1995), cosmologies of the past, rituals and myths about sovereignty adherent to institute of the king were replaced by new thinking that constructed world's order on the basis of 
symmetry, equilibrium between elements of which the cosmos consisted. ${ }^{14}$ The guarantee of political and social symmetry was Logos, and methodology of dialectics that imprinted the shape of science for next generations. This was the socio-cultural background for Greek proportional comprehension of phenomena.

The main problem coming into discussion on proportions and ratios is appearance of irrational number, which was the essential issue stemming from incommensurability of geometrical parameters. The incommensurability adumbrated musical ratios themselves and also their application into tetrachord establishment. The discovery of irrationality in geometry and mathematics is accredited to Pythagoreans (although by all accounts the issue itself is much older). It related to incommensurability of particular vectors, namely the mean geometrical proportion also known as the golden section $\mathrm{a}: \mathrm{b}=\mathrm{b}: \mathrm{c}$, and the problem of ratio between side and diagonal within a square. The number determining the ratio between circumference and diameter (ratio $c: 1$ ) is known as $\pi$ - another number belonging to the set of irrational numbers. In fact, the question ancient scholar had posed was: what is the ratio between the idea of vector and the idea of circle, because circumference originated in combination - particular proportion figured in numbers - of these ideas.

Quod nota, in the course of solving these problems, there was no magnitude by the medium of which it could be possible to define e.g. length. According to Platonian geometry, magnitude is not identical with idea. The argument is that it is not possible to preserve magnitude per se without an object; particular magnitude is designated by particular object. Therefore irrational numbers were defined through geometrical argumentation, e.g. irrational number $\sqrt{2}$ is defined as the ratio $\sqrt{2}: 1$ between diagonal and side, and not as a definite longitude of particular diagonal. This proportion could be preserved, as well as the number itself, independently from matter. It follows that these ideas are invariants, absolute parameters superior to ever-changing forms of outer world.

Also in music, there was no magnitude of sound (i.e. frequency). Therefore, the Greek tonal system had to be proved by means of geometrical analogies. There was crucial to find the geometrical parameter with direct relevance to the pitch discreteness. These parameters were: vector (idealized string, later monochord technology), area and cubage. It is worth of mention that all of these parameters have different geometrical solutions despite their same result - fundamental ratio $2: 1$. The most elementary solution is definition by two vectors in ratio $2: 1=a: b$ (see Figure 1$)$.

$\mathrm{a}$ b

Figure 1

\footnotetext{
14 Vernant, Jean-Piere, The Origins of Greek Thought (Cornell University Press 1982), p. 49-68.
} 
The methodology of vector (two referential points) in music ratio definition was in use since Euclid. The direct relevance between the pitch and vector lengthiness was a rudimental assumption for canon technology.

The second solution involves incommensurability (in terms of vector) between the side of a square and its diagonal. This problem is known as Pythagorean theorem (see Figure 2).

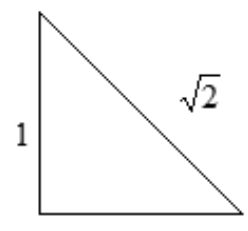

1

Figure 2

Incommensurability is resolved by the area reference of the side and its diagonal (Figure 3):
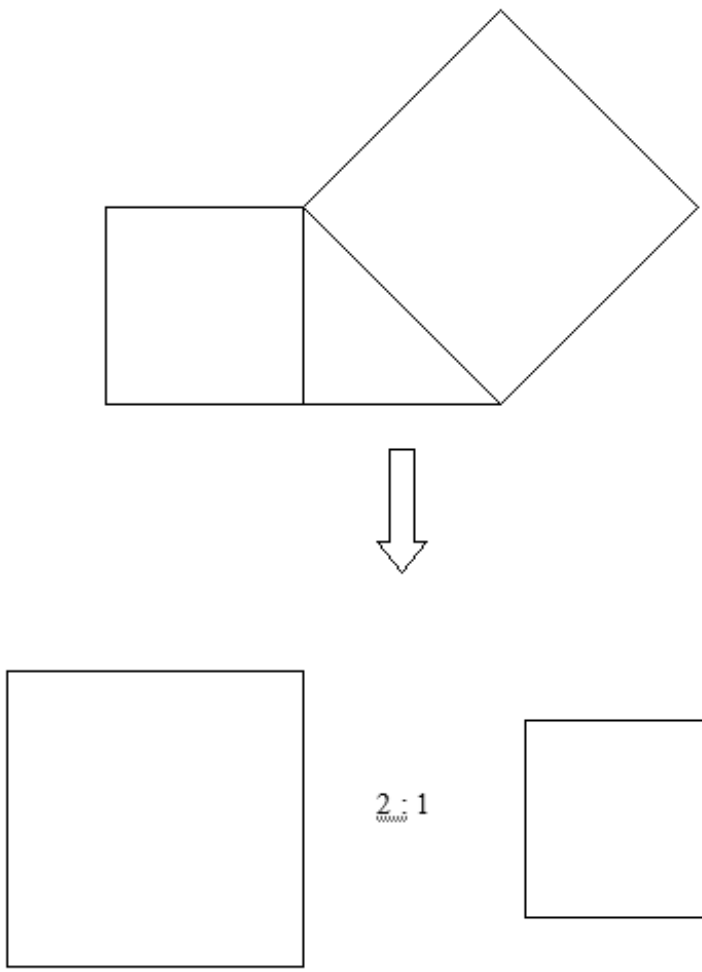

$2: 1$

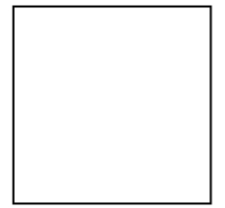

Figure 3 
The area above the diagonal is to the area above the side in ratio $2: 1$ (although the ratio between diagonal and side is irrational). It is the area or square definition of the fundamental ratio through applying the Pythagorean theorem. Moreover, the diagonal $\sqrt{2}$ is in fact, the diminium (half) ratio of an octave. From whence it follows that musical interval of an octave could not be divided into two equal parts. ${ }^{15}$ Therefore it was not possible to establish a regular (tempered) intonation on the basis of musical ratios. ${ }^{16}$

Finally, the cubic definition of this ratio is so-called Delian problem - one of fundamental issues of Greek geometry: duplication of the cube, i.e. finding the ratio between two sides of cubes in cubage of $2: 1$ (Figure 4):

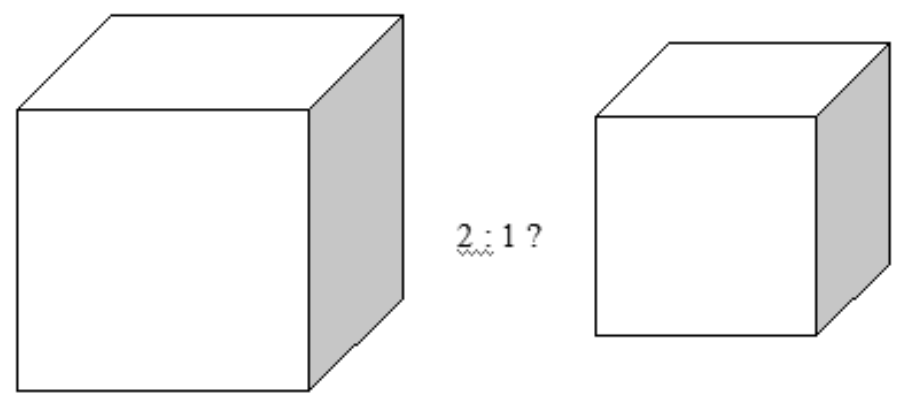

Figure 4

Basic numerical ratios in geometry were similar to those of music. However, what was the fundamental axiom for relation between geometrical parameters and sound? To a greater or lesser degree it was an experience, ${ }^{17}$ but the concept had to be drawn from so-called Platonian geometry, ${ }^{18}$ which could be summarized as follows:

1. Geometrical world is viewed through real world; ideas are superior to them.

2. The best way of entering into the world of ideas is through geometry, geometrical object are ideal, i.e. they not contain matter.

15 This was the fundamental controversy between Aristoxenian and Pythagorean approach to the proportion (i.e. musical ratio) division. See Boethian argumentation against Aristoxenus: Boethius, Anicius Manlius Severinus, Fundamentals of Music, Calvin M. Bower, Claude V. Palisca, Eds. (New Haven \& London, Yale University Press, 1989), p. 88-91: chapter "Demonstration against Aristoxenus that a superparticular ratio cannot be divided into equal parts, and for that reason neither the tone".

16 Celhoffer, Martin, "[the root of] 2 [is not equal to] a : b as a tonality issue”, Musicologica Brunensia, Vol. 45 (2010), No. 1-2, p. 69-76.

17 Surprisingly, also in Pythagorean thought, see Boethius, Anicius Manlius Severinus, Fundamentals of Music, Calvin M. Bower, Claude V. Palisca, Eds. (New Haven \& London, Yale University Press, 1989), p. 17.

18 Vopěnka, P., Rozpravy s geometrií (Prague, 1989). 
3. Ideas are: rectitude, curvature etc., they could not be viewed themselves, but by the medium of geometrical object.

4. Vector has participation on the idea of rectitude, i.e. each geometrical object has participation on particular idea or ideas.

5. The ontology of whatever object is not relevant to the object itself, but to the ideas it participates.

6. Two geometrical objects are identical if they have the same participation.

7. In real objects ideas are less recognizable, because matter obscures them.

8. Physical magnitude is not identical with idea, because we cannot preserve magnitude without object; an object determines the magnitude.

9. Verification is made by recognition of particular ideas in the object, and by definition of their relation - ratio.

Therefore numeric proportions are the numeric definitions of invariable ideas. These could participate in geometry, in decorative symmetry and, of course, in music.

Contrary to the Platonian geometry and its dialectics, there was a Pythagorean doctrine of tetractys that was to a particular extent similar to the geometrical rules, and therefore applicable to musical ratios. Tetractys is identical with the third triangle number 10 :

o

o 0

O $\quad 0 \quad 0$

$\begin{array}{llll}0 & 0 & 0 & 0\end{array}$

The mathematical formulae of tetractys: $1+2+3+4=10 ; 1 \times 2 \times 3 \times 4=24$.

Musical ratios derived from tetractys: $1: 1,1: 2,2: 3,3: 4$, no other fundamental ratios were allowed except their combinations. This means that other ratios within the tetrachord should be derived from these fundamental ratios. The hierarchy of ratios is drawn from its position within the triangle: unison, octave, fifth, fourth.

The crucial aspect in musical ratios establishment was geometrical conception based on ancient numerology. We also could assume that musical ratios in its early form did not represent all aspects of musical practice. They were comprehended as musical invariants. Forasmuch as basic quantities (in terms of modern physics) were not codified and known, invariant universal order was accredited to governance of numerical proportions. The genesis of this idealization of perceived world goes far back to Paleolithic era where was set up the foundation for abstract thinking. The human takes over the role of nature in hominid evolution by using technologies and promotes the artificial order of schematised world. The fundamental factor of this conceptualisation of outer world was by all accounts the appearance of awareness of self as the basic constituent of hominid culture. This brief study might provide an anthropological background for further discussion upon the philosophical basis of Greek music theory. 


\section{Hudební proporce starověku}

Shrnutí

Studie je úvahou nad možnými antropologickými a kulturními předpoklady pro etablování číselné proporce jako analogie $\mathrm{k}$ hudebním intervalům. Zabývá se vztahem mezi ranými projevy geometrie a aritmetiky a klade si otázku, do jaké míry tvoři tyto vztahy nutný předpoklad pro idealizované uchopení tónových struktur, jak je známe z pythagorejské tradice.

\section{Musik Proportionen der Antike}

\section{Zusammenfassung}

Diese Studie geht den möglichen anthropologischen und kulturellen Voraussetzungen für die Errichtung der Zahlenverhältnisse als Analogie zum musikalischen Intervallen nach. Es befasst sich mit der Beziehung zwischen frühen Ausprägungen der Geometrie und Arithmetik, und stellt sich die Frage: inwieweit sind diese Beziehungen eine notwendige Voraussetzung für eine idealisierte Auffassung von der aus der pythagoreischen Tradition bekannten Tonstrukturen.

\section{Klíčová slova}

Monochord; hudební proporce; pythagoreismus; kanon; tetrachord; tetractys.

\section{Key words}

Monochord; music ratio; Pythagoreism; canon; musical proportion; tetrachord; tetractys. 